\title{
Relações entre avaliação e comunicação: Perceções de dois professores de
}

\section{Matemática}

\section{Relations between assessment and communication: perceptions of two \\ mathematics teachers}

\author{
Cristina Martins*, António Guerreiro** \\ *Instituto Politécnico de Bragança, **Universidade do Algarve
}

\begin{abstract}
Resumo
A avaliação e a comunicação são dois processos fundamentais nas práticas letivas dos professores. Mas de que forma os professores os relacionam consciente e intencionalmente na sala de aula? Esta questão conduziunos ao desenvolvimento de um estudo cujo objetivo principal é compreender as relações existentes entre a avaliação e a comunicação nas práticas dos professores de matemática. Apresentamos uma investigação em curso e os resultados emergentes das entrevistas realizadas a dois dos participantes. É possível adiantar que o tipo de ensino preconizado na aula condiciona a comunicação e a avaliação praticada e a forma como o professor relaciona estes processos.

Palavras chave: avaliação, comunicação, práticas letivas, aula de matemática.
\end{abstract}

\begin{abstract}
Assessment and communication are two fundamental processes in the teachers' practices. But in what way do teachers consciously and intentionally relate them in the classroom? This issue has led us to develop an analysis whose main goal is to understand the relations arising between assessment and communication in the practices of mathematics teachers. We present an ongoing investigation and the results of the interviews with two participants. It is possible to advance that the kind of teaching advocated in class conditions both communication and the assessment implemented, and the way the teachers interrelate these processes.

Keywords: assessment, communication, teaching practices, mathematics class.
\end{abstract}

\section{Apresentação e Metodologia do Estudo}

A avaliação e a comunicação apresentam-se como dois processos estruturantes nas práticas profissionais dos professores em sala de aula. Esta perceção conduziu-nos ao desenvolvimento de uma investigação cujo objetivo principal é estudar as relações entre avaliação e comunicação, num contexto colaborativo, tendo em vista proporcionar significativas aprendizagens matemáticas aos alunos. Deste modo, conhecer as perceções dos professores constituiu o alicerce base na estruturação da investigação empírica e cremos que sustente a criação de conhecimento neste âmbito.

Os participantes neste estudo, para além dos investigadores (autores deste artigo), são quatro professores (dois professores e duas professoras) do $2 .^{\circ}$ ciclo do ensino básico (dois do distrito de Bragança e dois do distrito de Faro) que lecionam matemática neste nível de ensino.

Adotamos um design de investigação interpretativo, com uma componente de colaboração entre investigadores e professores participantes, com o intuito de interpretar, compreender e explicar significados, num contexto específico, tendo por propósito responder à questão de investigação: Que relação existe entre a avaliação e a comunicação nas aulas de matemática no $2 .^{\circ}$ ciclo do ensino básico (alunos entre os 10 e os 12 anos)?

A recolha de dados relativos à fase da perceção dos professores decorreu da realização duma entrevista semiestruturada aos professores participantes no estudo, tendo por intento averiguar as perceções dos professores do $2 .^{\circ}$ ciclo do ensino básico sobre a avaliação e a comunicação no contexto das suas práticas na aula de matemática.

As categorias e subcategorias de análise dos dados, delineadas tendo por base o enquadramento teórico de referência, com a clara intenção de, a partir delas, fazer emergir as relações entre a avaliação e a comunicação, a partir das perceções e as práticas profissionais dos professores. As categorias da avaliação e da comunicação estão enquadradas na perspetiva teórica da existência de avaliação das e para as aprendizagens (Fernandes, 2015) dos alunos e na dicotomia entre a comunicação matemática como instrumento de ensino e como interação entre os alunos e entre estes e o professor (Menezes, Guerreiro, Martinho \& Tomás Ferreira, 2013).

\section{Perceções sobre avaliação e comunicação de Manuel e Martins}

Esta comunicação centra-se na análise comparativa das perceções dos professores Manuel e Martins. Manuel tem quinze anos de serviço docente no $2 .^{\circ}$ ciclo do ensino básico, embora tenha também lecionado anteriormente noutros ciclos de ensino, e leciona no distrito de Bragança, Portugal. Martins tem dezoito anos de serviço docente, nos $2 .^{\circ}$ e $3 .^{\circ}$ ciclos do ensino básico, e leciona no distrito de Faro, Portugal. As turmas do docente 
Martins têm poucos discentes (entre 12 a 15) em virtude de trabalhar num agrupamento de escolas TEIP Território Educativo de Intervenção Prioritária.

\section{Perceções sobre avaliação na aula de matemática}

A avaliação na aula é entendida nas vertentes da avaliação das e para as aprendizagens e tenta facilitar a aquisição dos conhecimentos matemáticos pelos alunos, através de uma forte ação reguladora permanente, especialmente nos contextos socioeducativos desfavorecidos.

Conceito de avaliação. Quando Manuel se refere ao conceito de avaliação centra-se essencialmente no processo, caracterizando como diagnóstico, ou seja, avançando com uma perspetiva de avaliação para a aprendizagem:

Todo o tipo de avaliação que fazemos é uma avaliação diagnóstica e que contribui para a formação do próprio aluno e claro como um propósito importante que é a recolha de elementos para depois, no final do ano ou período, aí sim, atribuir um nível [Manuel].

Martins associa à avaliação da aprendizagem, defendendo que a avaliação é "aferir aquilo que os miúdos aprendem ou não" [Martins], entendendo a avaliação como uma retroação em relação ao discurso do professor, "aferir se a mensagem está a passar, se não está a passar" [Martins].

Em síntese, os professores recorrem à avaliação das e para as aprendizagens, com uma forte componente centrada nos conhecimentos dos alunos, seja uma avaliação diagnóstica ou sumativa.

Componentes integrantes da avaliação. Manuel associa à avaliação dos conhecimentos aos testes e elenca outros elementos a considerar no processo, valorizando a realização de trabalhos de casa:

Para além dos aspetos que estão relacionados com o conhecimento, digamos assim, aquilo que eles produzem no teste, há outros aspetos que entram como, por exemplo, o comportamento do aluno dentro da sala de aula, a sua participação, a atitude em sala de aula, a forma como se relaciona com os colegas (...) As tarefas de casa, que eu marco sempre, para a criação de hábitos de trabalho, responsabilidade, obrigar o aluno, ele próprio ir construindo a sua aprendizagem e a identificar as suas dificuldades [Manuel].

Associada às componentes, surge a valorização que cada uma assume na avaliação final da aprendizagem e por quem são definidas:

Os critérios de avaliação do agrupamento e de disciplina são decididos ao nível do departamento por ciclos e até por anos de escolaridade. Temos alguma ponderação que é atribuída à parte de conhecimento $\mathrm{e}$ à parte das atitudes, no nosso caso anda nos $75 \%$, $25 \%$, também pode ser $80 \%, 20 \%$. Também depende dos alunos em causa, se são alunos que revelem alguma dificuldade de aprendizagem, estejam integrados em algum programa, tem de fazer-se um ajuste [Manuel].

De igual modo Martins relata que, no seu agrupamento de escolas (TEIP), os professores questionaram o peso do conhecimento na avaliação e optaram por reforçar o peso das atitudes e valores (numa relação 70/30):

Estamos a dar um peso excessivo à parte dos conhecimentos e tem que haver aqui um equilíbrio porque a natureza dos nossos alunos assim pedia ... valorizar mais um pouco essa outra questão ... estamos a falar na ordem dos 30/70 ... é aí nesses 30 que cabe a parte da responsabilidade, dos trabalhos [Martins].

Em ambos os casos, os professores criticam a valorização excessiva da componente de conhecimento em detrimento das atitudes e valores, particularmente nos alunos com contextos socioeconómicos desfavorecidos.

Instrumentos de avaliação dos alunos. Não se desvinculando que o teste é um instrumento de avaliação imprescindível para avaliar o conhecimento, Manuel revela a importância de se ter em consideração a "especificidade das próprias turmas" [Manuel] e dá um exemplo de como concretiza a sua ideia:

$\mathrm{O}$ ano passado tive uma turma muito complicada, sabia que para que os alunos tivessem sucesso tinha que criar pequenos momentos de avaliação semanais. (...). Esses pequenos trabalhos, que iam fazendo, iriam entrar num somatório de várias tarefas que fariam parte da classificação do teste final. E pronto, conseguiu-se [Manuel].

De igual modo, os instrumentos mais utilizados na avaliação dos alunos do professor Martins têm as características dos testes escritos formais - "nunca fazer menos de dois momentos de avaliação [por período letivo]" [Martins], mesmo em formatos reduzidos, numa perspetiva de avaliação da aprendizagem: "todas as semanas temos um momento de avaliação, eles já sabem que vão ter aquele momento de avaliação, são duas ou três questões" [Martins], no mesmo sentido de valorizar o trabalho contínuo dos alunos.

Para além dos registos escritos, existe uma avaliação para a aprendizagem com características de feedback do professor Martins, com uma natureza mais oral: "[o feedback] acaba por ser mais oral, individualizado" [Martins].

As estratégias utilizadas pelos professores para promoverem o sucesso e a aprendizagem dos alunos são similares, através da realização de momentos contínuos de avaliação, em favor de uma avaliação reguladora das aprendizagens semanais.

Funções da avaliação no processo de ensino e de aprendizagem dos alunos. No seguimento da importância que atribui à realização de questões semanais, Manuel torna clara a função reguladora da avaliação, quer para o aluno quer para o professor:

O objetivo é que seja útil para os alunos, e no meio disto tudo que também seja útil para mim, no sentido que me permita recolher mais informação que possa utilizar na avaliação final. (...). Portanto, na perspetiva do professor, a avaliação serve para acompanhar a evolução do aluno, conseguir perceber em que ponto é que ele está e as suas dificuldades para o poder alertar para isso [Manuel].

Alerta, contudo, que a desmotivação dos alunos pela aprendizagem é um entrave ao bom desenvolvimento do 
processo de ensino e de aprendizagem e consequentemente de avaliação:

Depois, também, há um outro aspeto, tem a ver com a motivação, muitas vezes não só com a motivação de quem ensina, mas a motivação do aluno para a aprendizagem e utilizando um bocadinho esta máxima: «Não se ensina a quem não quer aprender», hoje nós temos muito esse problema que é a valorização da escola [Manuel].

Martins entende que a avaliação deve ser partilhada com os alunos - "vale a pena partilhar com eles [alunos] a avaliação, vale a pena partilhar, ... tenho a necessidade de partilhar com eles" [Martins] - e que uma avaliação positiva tem nos alunos um papel motivador em relação à matemática - "a avaliação na matemática tem muito, muito, muito a fazer no estimulo dele para a disciplina ... é o momento em que a coisa corre bem ... o bom resultado a matemática ... acaba por ser um estímulo" [Martins] - e também em relação às restantes disciplinas. Para o professor Martins, a avaliação dos alunos também tem a função de o questionar sobre o seu ensino:

Se formalmente a gente avalia determinado conteúdo e se chegas à conclusão que grande parte dos teus alunos não conseguem fazer as coisas com sucesso, então alguma coisa está mal, temos que desconstruir um bocado isto e ver onde é que é, o que é que foi, acaba por ser uma base para ... das duas uma, ou continuar como as coisas estão ou calma, vamos travar, vamos voltar a trás e vamos ver o que está aqui a falhar [Martins].

Nesta dimensão de instrução, o professor questiona-se sobre a natureza dos erros dos alunos e sobre as resoluções singulares - "um exercício proposto pelo livro ... chama-te à atenção um erro recorrente que muitos deles estão a ter e também te chama à atenção como é que alguns deles estão a chegar a outro sítio" [Martins] valorizando uma dimensão de aprendizagem profissional através das resoluções das tarefas pelos alunos.

Na dimensão institucional, Martins considera que está constantemente a ser escrutinado em relação à avaliação dos alunos, dado tratar-se de um agrupamento de escolas TEIP:

No nosso caso particular, [a direção do agrupamento de escolas] preocupa-se e muito, tanto assim que ... somos mais observados do que qualquer um, somos escrutinados, somos postos contra a parede, dizer assim «meus amigos, atenção, isto não está bem, está aqui qualquer coisa que temos de mudar, o que é que precisam?» [Martins].

A avaliação das aprendizagens dos alunos, associada ao sucesso escolar, parece constituir uma preocupação constante do professor. Neste sentido, ambos os docentes definem estratégias de promoção dos conhecimentos dos alunos, apesar dos contextos sociais e culturais desfavoráveis, por vezes, em consonância com a política educativa da instituição escolar.

\section{Perceções sobre comunicação na aula de matemática}

A comunicação assume o papel de instrumento comunicativo e o de processo de interação entre os alunos e entre estes e o professor. Nestes contextos, o papel da linguagem surge com uma centralidade na aula, assumindo um papel predominante no ensino e na aprendizagem da matemática.

\section{Conceito de comunicação na aula de matemática}

Manuel associa o conceito de comunicação ao que considera ser o seu objetivo, concretamente refere:

É fazer passar a mensagem de maneira a que seja entendida por quem é o alvo dessa mesma mensagem. Tudo é comunicação. Dentro do espaço da aula, em que o professor consegue trabalhar o assunto, eu acho que esse é um período de comunicação, no qual o professor aproveita para destrinçar, esmiuçar toda a mensagem que pretende transmitir [Manuel].

De igual modo, Martins assume a comunicação centrada na mensagem, em duas perspetivas distintas: comunicação simbólica, referente ao reflexo de atitudes, e comunicação discursiva, dividida em duas dimensões da linguagem, linguagem formal da matemática e linguagem informal ou metafórica. Nas suas palavras:

Temos claramente dois momentos de comunicação, já para não falar logo quando o professor chega ... o professor hoje vem de preto ... vem com uma cara daquelas ... vem contente (...) linguagem formal da matemática (...) uma linguagem mais terra a terra para eles [Martins].

Ambos os professores perspetivam a comunicação como um instrumento linguístico caracterizado por uma mensagem numa linguagem especifica.

Características da comunicação na aula de matemática. Manuel concentra-se nas fases de uma aula de resolução de problemas, localizando a comunicação na fase de debate sobre o problema colocado:

Eu normalmente começo sempre pela tentativa de resolução de um problema ou colocando uma questão, eu pretendo fazer isto e como é que chegamos lá. (...). No debate para a resolução de problemas, há comunicação do professor para com o aluno ou entre os alunos, centrado nesse mesmo problema [Manuel].

Martins caracteriza a comunicação na sala de aula com uma dimensão de interação entre o professor e os alunos - "entre eu e eles" [Martins] - defendendo que existe muita dificuldade na interação comunicativa entre os alunos, em parte devido à natureza da turma (alunos com contextos socioeducativos desfavoráveis) - "lá está, devido à própria natureza daquelas turmas, eles são muito desorganizados a comunicar entre eles ... muitas vezes não conseguem respeitar-se uns aos outros" [Martins]. Salienta que os alunos têm poucos hábitos de argumentação, o que dificulta o processo avaliativo: "a capacidade de argumentação deles em sala de aula sobre um determinado assunto, confesso que não é ... se calhar não é por aí que eu vou buscar a tal avaliação" [Martins].

Este professor rejeita um discurso exclusivamente unidirecional ou colaborativo, defende o questionamento com perguntas direcionadas para os conteúdos - "às vezes com pequenas perguntinhas ... às vezes com uma pequena revisão, com uma pequena pergunta ... leva a uma determinada resposta [que faça clique no conhecimento do aluno]" [Martins] - mas rejeita, ironizando, as perguntas em que os alunos se limitam a 
terminar as frases do professor - "dois ao quadrado é qua..., qua..., qua..., para ele [o aluno] dizer tro" [Martins].

Em síntese, as características principais da comunicação matemática em sala de aula assentam na relação do professor com os alunos e destes com o professor em detrimento da comunicação entre os alunos, tendo sempre como contexto as características da linguagem matemática.

Formas de comunicação na aula de matemática. $\mathrm{Na}$ continuidade do exposto sobre as características da comunicação na aula de Matemática, Manuel identifica a comunicação escrita e a comunicação oral: "Essa comunicação [centrada na resolução de problemas] tanto pode ser escrita como oral, na parte escrita tanto pode ser utilizando a linguagem matemática quer utilizando um esquema, um gráfico" [Manuel].

Quando questionado diretamente sobre qual o tipo de comunicação que privilegia, Manuel tem dificuldade em assumir uma posição:

É-me difícil dizer, acho que nós aliamos uma coisa à outra. São muito privilegiados os registos, aliás eu utilizo muito esquemas, vou muito por aí, até para mim próprio. Acho que privilegio tanto uma como a outra. Os alunos preocupam-se muito com o resultado. Eu digo-lhes que me interessa mais o processo e, portanto, privilegio isso, a forma de construção do pensamento e isso, a meu ver, tem de ser registado. Pensando bem, se calhar privilegio os aspetos da comunicação escrita, associando-os aos registos [Manuel].

Além disso, ao revelar a existência de dificuldades de comunicação na aula de Matemática, identifica, simultaneamente, a linguagem específica da matemática e a linguagem usual na língua materna:

Temos problemas na comunicação quer na comunicação matemática porque há desconhecimento de alguma simbologia ou daquilo que é comunicar em matemática, mas também há um desconhecimento ao nível da outra comunicação, a comunicação em geral, sendo este o grande problema na resolução de problemas [Manuel].

Martins assume que "a comunicação não é só no discurso, mas também no que leem, no que trabalham" [Martins]. Considera que, nas suas aulas, existe um significativo desequilíbrio entre a oralidade e a escrita, em parte devido à dimensão da turma - "claramente desequilibrada ... no discurso ... mais oral ... a escrita é mais para o registo desses momentos" [Martins]. A oralidade domina a aula - "o discurso [oral] faz parte de grande parte da aula" [Martins] - e a escrita caracterizase pelo registo de definiçõos e sínteses - "faz sentido os miúdos registarem ... sínteses, alguma definiçãozinha que seja necessária" [Martins].

A comunicação oral e escrita é permanente na sala de aula, contudo o discurso escrito surge como suporte do discurso oral e é valorizado pela sua natureza de registo e de permanência para além do momento de sala de aula.

Funções da comunicação no processo de ensino e de aprendizagem dos alunos. Para Manuel, a associação da comunicação a tudo que se passa na sala de aula é parte integrante da avaliação:
No início quando falámos da avaliação disse que tinha sempre em conta todo o ambiente da sala de aula, onde obviamente a comunicação é um aspeto central. Penso, que não há professor nenhum que não a considera sempre. Umas vezes mais, outras vezes menos. Há turmas onde isso é possível, mas eu acho que é por aí que se deve insistir [Manuel].

Especifica, ainda, a importância da comunicação como atribuindo-lhe uma função de colaboração entre os alunos na compreensão dos conhecimentos:

Se houver comunicação entre os alunos, cria mais significado aquilo que conseguem, o pouco ou muito que possam conseguir. No caso de uma turma dita normal e mais ou menos equilibrada dentro da heterogeneidade das turmas que temos, conseguimos, que aqueles que entenderam, que percecionaram as ideias matemáticas, expliquem aos outros, pela sua própria linguagem [Manuel].

Martins assume que se questiona a propósito da sua própria comunicação, particularmente na eficácia do seu discurso ou da mensagem, quando avalia os alunos e os resultados ficam aquém das expetativas:

A avaliação que eu estou a fazer está um bocadinho aquém daquilo que eu esperava ... será que isto também tem a ver com a comunicação que eu tenho? será que a minha mensagem está a passar? será que é da melhor forma? haverá aqui alguma alternativa? a minha mensagem não está a passar por algum motivo? [Martins].

A comunicação como interação entre os alunos e como instrumento do professor surge como um pressuposto da construção do conhecimento, através do ensino e da partilha de conhecimentos matemáticos.

\section{Cruzando perspetivas}

A articulação entre avaliação e comunicação na aula de matemática resulta da comunicação poder servir como instrumento de ensino e de avaliação e da avaliação poder conduzir à criação de momentos ricos de comunicação. Neste sentido, reafirmamos que o conhecimento das perceções e das práticas dos professores constitui o alicerce base na estruturação da investigação empírica que sustentará a criação de conhecimentos.

Manuel e Martins, associado ao conceito de avaliação, deixam clara a ideia da avaliação das e para as aprendizagens, assumindo-a com caráter diagnóstico e formativo. Como refere Fernandes (2015), parece ser inevitável a consideração da vertente de avaliação das aprendizagens, mas deve igualmente assumir-se numa perspetiva de avaliação para as aprendizagens, na qual os alunos são chamados a participar e os professores distribuem regularmente feedback das aprendizagens por eles realizadas.

Em ambos os casos, os professores criticam a valorização excessiva da componente de conhecimento em detrimento das atitudes e valores, particularmente nos alunos com contextos socioeconómicos desfavorecidos. Em sintonia com esta ideia, Rafael (1998) considera fundamental que o processo de avaliação inclua as componentes do conhecimento e das atitudes e valores, da forma de agir e pensar, bem como o empenho e a 
dedicação dos alunos face às tarefas propostas, o que só será possível através da recolha e registo diversificados de informação.

Sobre este ponto especificamente, os professores apresentam ideias similares, sendo que as estratégias por eles utilizadas para promoverem o sucesso e a aprendizagem dos alunos, inclui a realização de momentos contínuos de avaliação, em favor de uma avaliação reguladora das aprendizagens semanais. De facto, nas perceções destes professores sobressai a função reguladora da avaliação, quer para o aluno quer para o professor, surgindo, neste contexto, a importância da motivação dos alunos.

Manuel considera que a [constante] desmotivação é um entrave ao processo de ensino e aprendizagem e Martins considera que uma avaliação positiva pode servir para motivar os alunos. Segundo Pinto \& Santos (2006), para que haja regulação é necessário que, por parte do professor:

1. Em termos do fazer que haja um processo de recolha de informação oportuno e adequado e um quadro teórico que permita interpretar essas informações, fornecer pistas ou orientações para a acção reguladora e proporcionar situações ou materiais que tornem essa tarefa exequível.

2. Em termos das atitudes que haja uma vontade de praticar este tipo de avaliação, que haja um aceitar mudar as formas de trabalhar em termos do processo de ensino-aprendizagem (p. 103).

Manuel e Martins perspetivam a comunicação matemática como um instrumento linguístico caracterizado por uma mensagem numa linguagem especifica. Nesta perspetiva, a comunicação tem um forte pendor semiótico em que se valoriza a significação, a interpretação e o valor informativo das mensagens que os sujeitos trocam entre si. A compreensão da complexidade das aprendizagens deve ter em conta a importância e a variedade das representações semióticas utilizadas em matemática e a explicitação dos processos cognitivos de passagem entre diferentes representações semióticas (Duval, 2006).

$\mathrm{Na}$ ótica de Brendefur e Frykholm (2000), a comunicação na aula de matemática pode resultar num maior controlo do professor ou numa centralidade no pensamento do aluno. Neste sentido, estes professores, quando abordam as características da comunicação na aula de matemática, consideram que esta assenta na relação do professor com os alunos e destes com o professor com menor evidencia da comunicação entre os alunos, tendo sempre como contexto as características da linguagem matemática, revelando uma centralidade do discurso do docente.

As formas de comunicação oral e escrita perspetivamse como processos valorativos na construção do conhecimento (Cândido, 2001; Powell \& Bairral, 2006). Particularmente, o questionamento oral (Mason, 2000) ou escrito surge como um processo de regulação das aprendizagens (Santos, 2004), podendo assumir uma natureza avaliativa, mas também a possibilidade de partilha comunicativa entre intervenientes. Nesta ótica, Manuel e Martins valorizam a comunicação oral e escrita, as quais são permanentes na sala de aula, contudo o discurso escrito surge como suporte do discurso oral e é valorizado pela sua natureza de registo e de permanência para além do momento de sala de aula.

Para Menezes, Guerreiro, Martinho e Tomás Ferreira (2013), o processo de comunicação estrutura as interações entre os alunos e entre estes e o professor e condiciona o processo de ensino e de aprendizagem, assumindo o domínio comunicativo do professor na sala de aula ou, em contrapartida, sustentando a partilha de conhecimento entre todos os intervenientes. Esta perspetiva é reforçada por estes professores ao defenderem a comunicação como interação entre os alunos e como instrumento do professor na construção do conhecimento, através do ensino e partilha de conhecimentos matemáticos.

Para finalizar, torna-se evidente para nós que o tipo de ensino preconizado e desenvolvido em sala de aula condiciona a comunicação e avaliação praticadas, bem como a forma como o professor relaciona estes processos. Particularmente, o questionamento, oral e escrito, surge como a peça central na relação entre a avaliação e a comunicação.

\section{Referencias}

Brendefur, J. \& Frykholm, J. (2000). Promoting Mathematical Communication in the Classroom: Two preservice teachers' conceptions and practices. Journal of Mathematics Teacher Education, 3, 125-153.

Cândido, P. (2001). Comunicação em Matemática. In Smole, K. \& Diniz, M. (Orgs.) Ler, escrever e resolver problemas (pp. 15-28). Porto Alegre: Artmed Editora.

Duval, R. (2006). Quelle sémiotique pour l'analyse de l'activité et des productions mathématiques? Relime Número Especial, 45-81.

Fernandes, D. (2015) Prefácio. In Neves, A. C. \& Ferreira, A. L. (2015). Avaliar é Preciso? Guia prático de avaliação para professores e formadores. Lisboa: Guerra \& Paz.

Mason, J. (2000). Asking mathematical questions mathematically. International Journal of Mathematical Education in Science and Technology, 31(1), 97-111.

Menezes, L., Guerreiro, A., Martinho, M. H., \& Tomás Ferreira, R. A. (2013). Essay on the role of teachers' questioning in inquiry-based mathematics teaching. Sysiphus, 1(3), 44-75.

Pinto, J., \& Santos, L. (2006). Modelos de avaliação das aprendizagens. Lisboa: Universidade Aberta.

Powell, A. \& Bairral, M. (2006). A escrita e o pensamento matemático. São Paulo: Papirus.

Rafael, M. (1998). Avaliação em Matemática no ensino secundário: Concepções e práticas de professores e expectativas de alunos (Tese de mestrado). Lisboa: Associação de Professores de Matemática.

Santos, L. (2004). La evaluación del aprendizage en matemáticas: orientaciones y retos. In J. Giménez; L. Santos, \& J. P. Ponte (Coords.). La actividade matemática en el aula: Homenaje a Paulo Abrantes (pp. 157-168). Barcelona: Biblioteca de Uno. 